\title{
Zooplankton abundance in subtropical waters: Is there a lunar cycle?*
}

\author{
S. HERNÁNDEZ-LEÓN ${ }^{1}$, C. ALMEIDA ${ }^{1}$, L. YEBRA ${ }^{1}$, J. ARÍSTEGUI ${ }^{1}$, \\ M.L. FERNÁNDEZ DE PUELLES ${ }^{2}$ and J. GARCÍA-BRAUN ${ }^{3}$ \\ ${ }^{1}$ Biological Oceanography Laboratory, Facultad de Ciencias del Mar, Campus Universitario de Tafira, 35017 Las Palmas \\ de GC, Islas Canarias. E-mail: santiago.hernandez-leon@biologia.ulpgc.es \\ ${ }^{2}$ Instituto Español de Oceanografía, Centro Costero de Baleares, P.O. Box 291, Palma de Mallorca. Islas Baleares. \\ ${ }^{3}$ Facultad de Ciencias Biológicas, Universidad de La Laguna, Av. Astrofísico Francisco Sánchez s/n, \\ Tenerife, Islas Canarias.
}

\begin{abstract}
SUMMARY: Based on historical data of abundance, we report evidence of changes in zooplankton abundance in the 0-200 $\mathrm{m}$ layer related to the moon cycle confirming that this phenomenon is produced in the marine environment, similarly to the one described for freshwater ecosystems. A clear decrease in the abundance of copepodites plus copepods was observed from the second to the fourth quarter of the moon when the seasonal variability was suppressed. During the full moon phase the large zooplankton and micronekton of the deep scattering layers (DSL) would not reach the upper mixed layer in order to avoid predation because of the relatively high level of illumination. Thus epipelagic zooplankton abundance increases as the effect of a lower predatory pressure. Conversely, during the new moon phase the diel migrants reach the surface waters and epiplankton abundance considerably decreases. Recent oceanic sediment trap data in subtropical waters indicate that the particle flux increases at about 30 days period. Thus, the effect of diel vertical migrants could promote not only the variability in their resources and the intensity of the active flux, but could also drive the variability in the gravitational flux.
\end{abstract}

Key words: lunar cycle, abundance, copepods, Canary Islands.

The assessment of biomass is critical for the study of physiological and mortality rates and fluxes in marine planktonic communities. It drives the magnitude of those fluxes which are of importance in order to assess the energy flux through the food web. Zooplankton biomass and abundance estimations produce a rather high variability (one to three orders of magnitude) compared to the measurements of rates (Huntley and Lopez, 1992). Therefore, biomass variability is of importance in sampling design in biological oceanographic studies at micro, meso

\footnotetext{
*Received January 21, 2000. Accepted July 10, 2000.
}

and large-scales as well as in the study of planktonic trends.

In subtropical waters, biomass and abundance are known to show short episodes of enrichments in late winter due to the seasonal cooling of the surface mixed layer. Recently, Hernández-León (1998) observed epipelagic copepod abundance in the Canary Island waters to show a high variability with maxima coinciding with the full moon during most of the annual cycle and suggesting a lunar cycle in zooplankton abundance in these waters. This variability was discussed on the basis that differences in predation during the moon cycle by the diel vertical 
migrants of the deep scattering layers (DSL's) could drive the differences in abundance. A similar phenomenon has been previously described in freshwater ecosystems (Gliwicks, 1986), showing that the increase in zooplankton during the second quarter of the moon and the posterior decrease after the full moon was related to differences in predation pressure by fish on zooplankton. Briefly, the process is related to the fact that during full moon and previous days, diel migrants do not reach the upper layers of the ocean as observed from acoustic data (Tarling et al., 1999) and field sampling (Clarke, 1973; Roger, 1974; Tarling et al., 1999). Deep scattering layers move vertically following determined isolumes (Boden and Kampa, 1969), and during the second quarter the moon illumination produces that day isolumes (around $500 \mathrm{~m}$ depth in subtropical waters) are found at 100-150 m depth during night (Hill, 1962). This behaviour will reduce the predation pressure in shallower waters allowing epipelagic zooplankton to increase in abundance. By contrast, epipelagic zooplankton are predated after the full moon as diel vertical migrants reach the surface waters due to darkness (see discussion in Hernández-León, 1998).

In this paper, we have reviewed historical data on zooplankton abundance in oceanic waters off the Canary Islands. The aim of the work was to see if the changes related to the lunar cycle of epipelagic
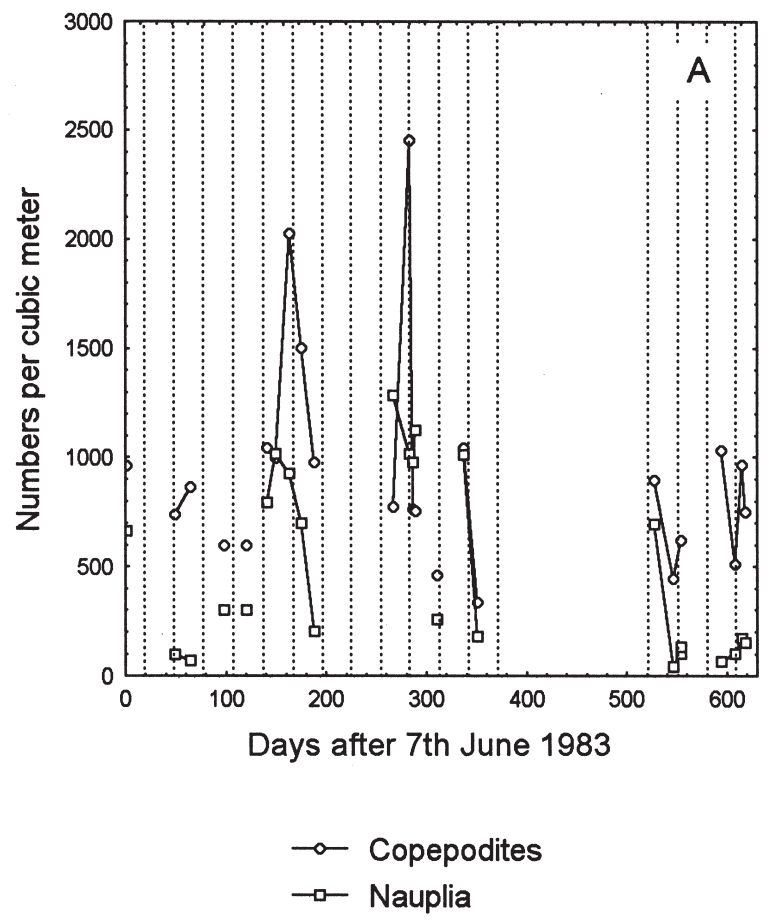

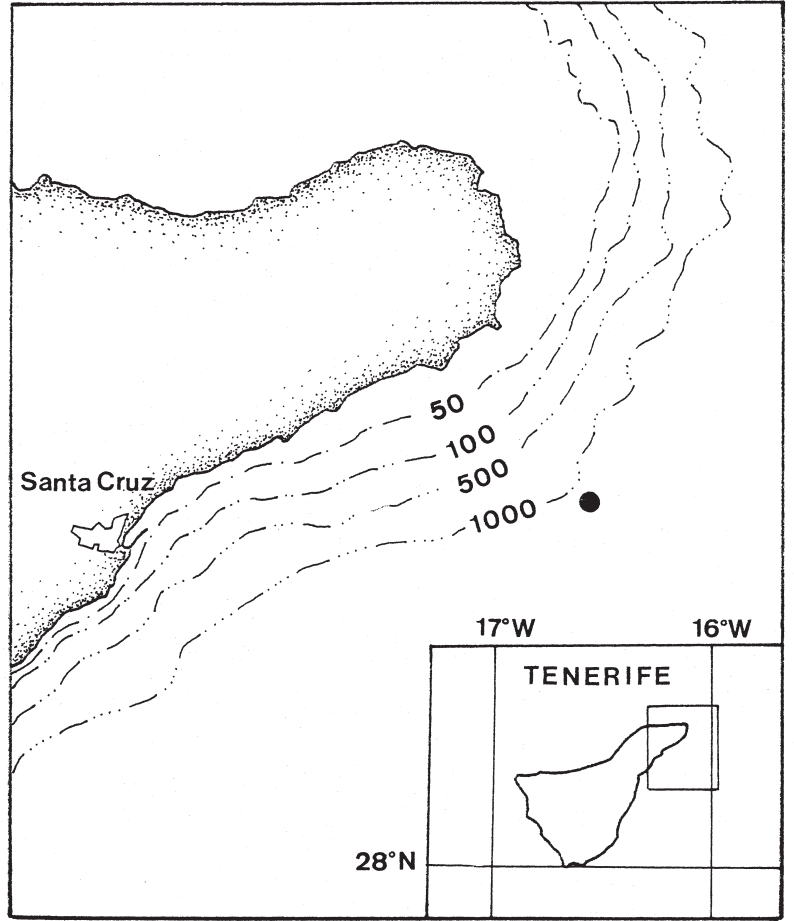

FIG. 1. - Location of the station to the north of Tenerife Island (Canary Islands).

(0-20 m) copepods reported by Hernández-León (1998) were observed as significant changes in the integrated $(0-200 \mathrm{~m})$ zooplankton abundance.

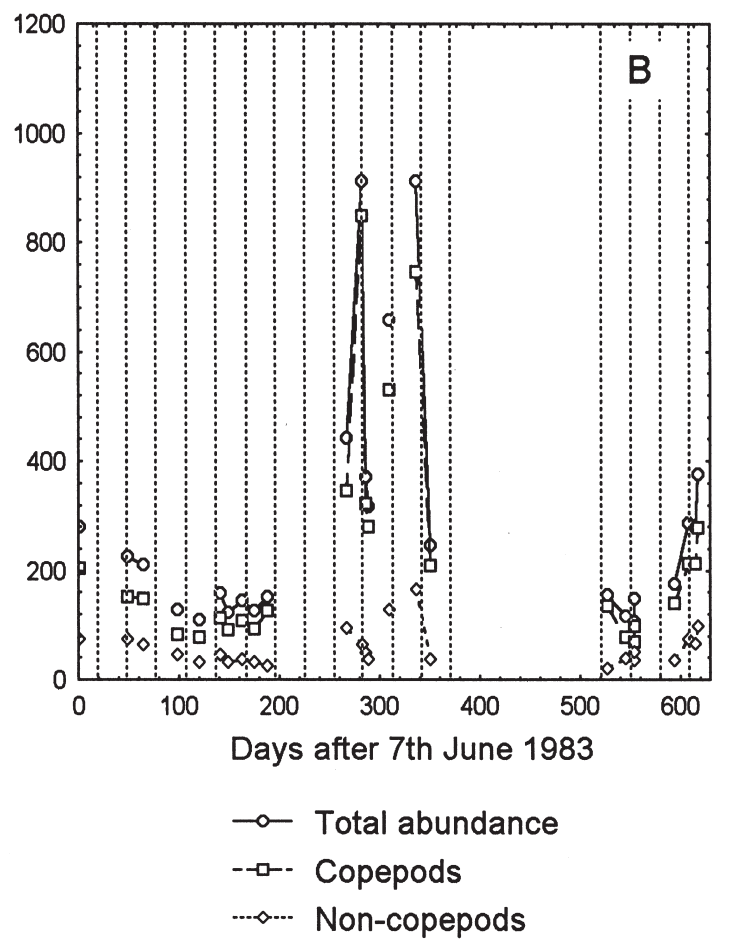

FIG. 2. - (A) Abundance of nauplia and copepodites in relation to the full moon (vertical dashed lines) during the annual cycles studied by Fernández de Puelles (1986). (B) As in (A) for the copepods, non-copepods and both. Connecting lines were drawn when the time interval between samples were less than 15 days. 
Data analysed in this study consists of bimonthly samples obtained between June 1983 and February 1985 by Fernández de Puelles (1986) at an oceanic station north of Tenerife Island over a depth of $1200 \mathrm{~m}$ (Fig. 1). Zooplankton samples were taken from oblique tows ( $200 \mathrm{~m}$ up to the surface) with two $50 \mathrm{~cm}$ Juday Bogorov nets equipped with 250 and $100 \mu \mathrm{m}$ mesh and General Oceanic flowmeters. Further details of sampling are given in Fernández de Puelles (1987), Fernández de Puelles and GarcíaBraun (1989) and Fernández de Puelles and GarcíaBraun (1996).

Sampling of zooplankton abundance reported by Fernández de Puelles (1986) in open ocean waters was on the basis of a 15-day interval (or more). These data were rather variable due to the differences in abundance among years and seasons. As
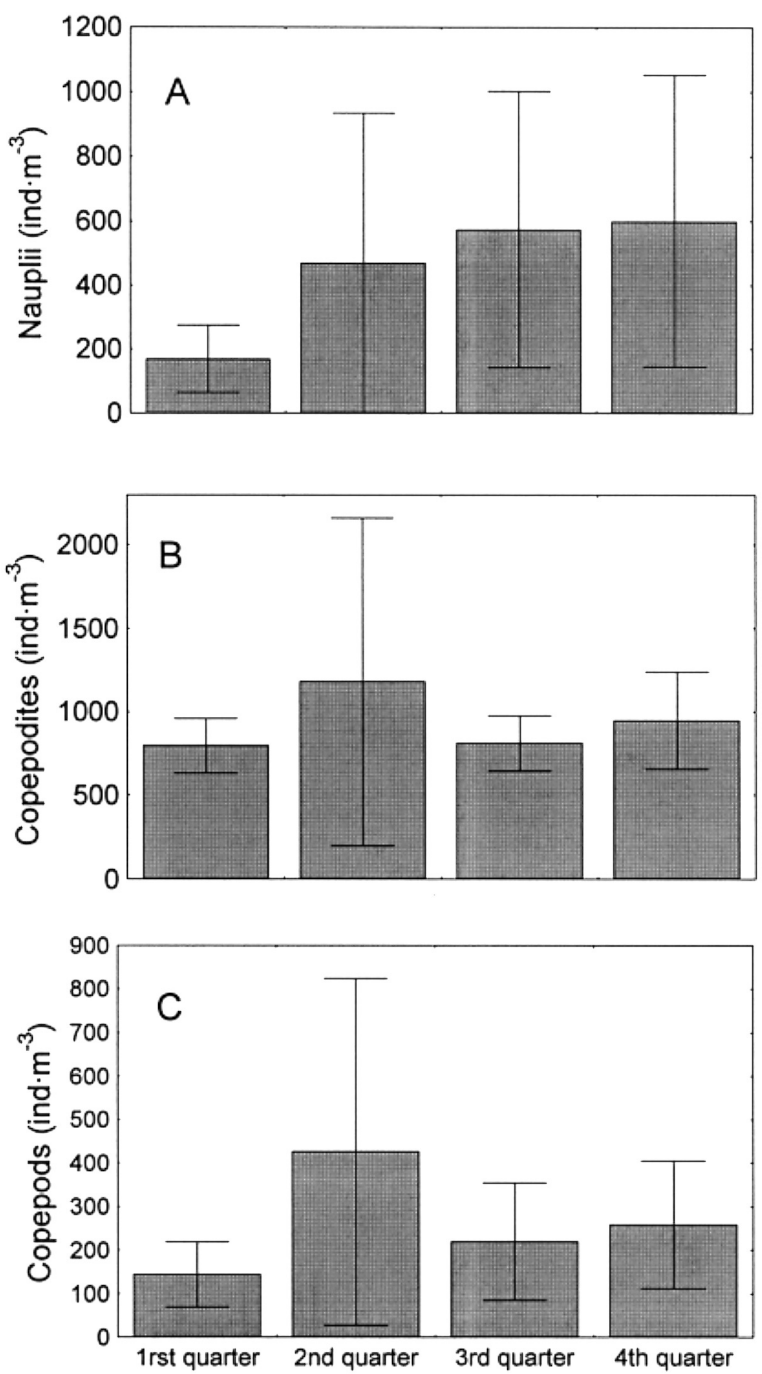

FIG. 3. - Abundance of (A) nauplia, (B) copepodites and (C) copepods collected in the $100 \mu \mathrm{m}$ mesh net and grouped in relation to the different periods of the moon cycle. The vertical lines are one standard deviation. expected, the observed pattern showed high abundance and variability during the late winter bloom and very low values during the most oligotrophic season (autumn) of the annual cycle (Fig. 2A,B). Nevertheless, it can be observed that during the late winter the highest abundance were roughly coincident with the full moon.

In order to study the effect of the moon cycle on the abundance and size structure of the zooplankton community, the abundance data were grouped and plotted in relation to the different quarters of the moon cycle: first from new to crescent moon, the second from crescent to full moon, the third from full to waning moon and the fourth from waning to new moon. Nauplia and copepodites obtained in the $100 \mu \mathrm{m}$ mesh net (Fig. 3A,B) showed non-significant differences (ANOVA, $\mathrm{p}>0.05$ ) between the dif-
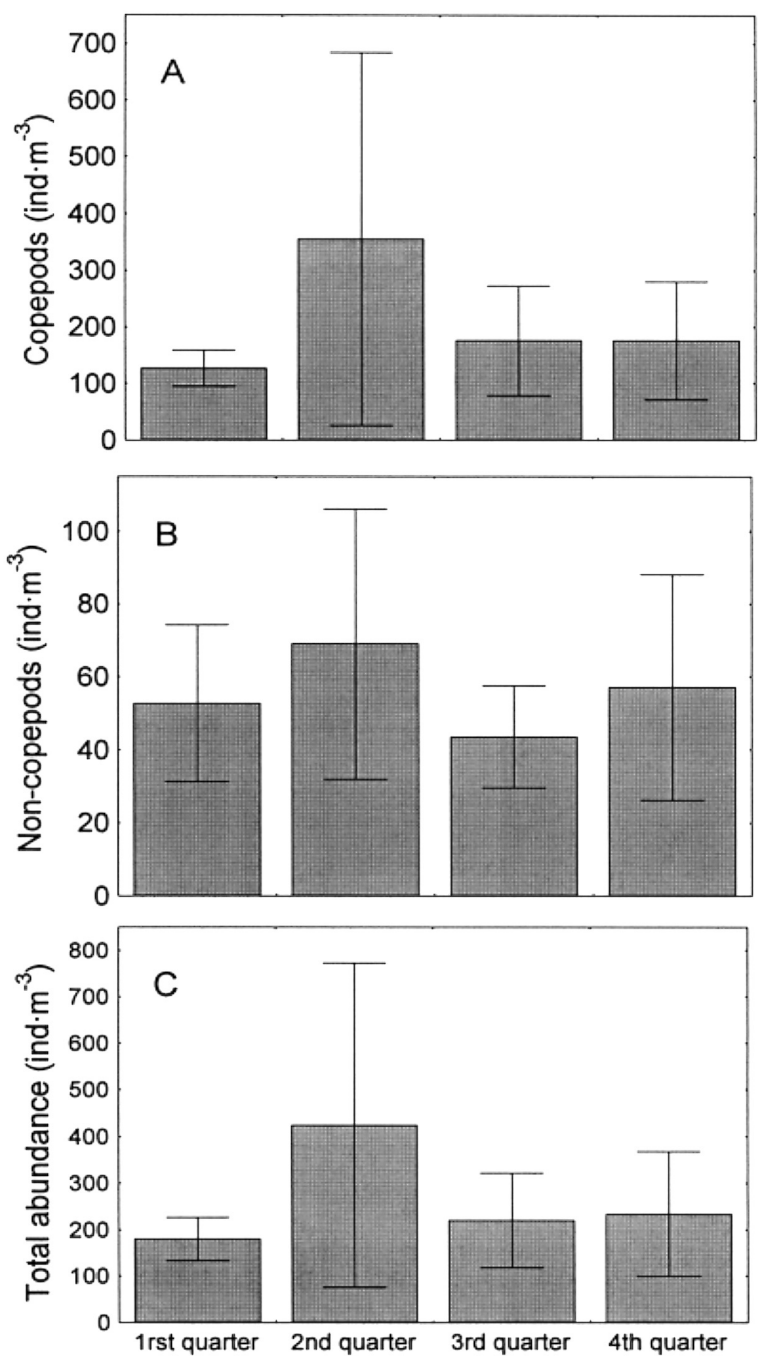

FIG. 4. - Abundance of (A) copepods, (B) non-copepods and (C) total abundance of organisms collected in the $250 \mu \mathrm{m}$ mesh net and grouped in relation to the different periods of the moon cycle. Vertical lines as in Figure 3. 
ferent quarters of the moon. Adult copepods sampled with this net showed apparently higher and more variable values during the second quarter of the moon (Fig. 3C). Differences between the second quarter of the moon and the others quarters were, however, not significantly different (ANOVA, $\mathrm{p}>0.05$ ). This variability is driven by the rather different abundance values observed during oligotrophic or bloom periods.

Adult copepods collected in the $250 \mu \mathrm{m}$ mesh net showed the same pattern as observed with the copepods collected in the $100 \mu \mathrm{m}$ mesh net with higher and more variable abundance during the second quarter of the moon cycle (Fig. 4A). However, differences between the second quarter and the others were statistically significant (ANOVA, $p<0.05$ ). No statistical differences were observed for the noncopepod mesozooplankton (Fig. 4B), while for the total abundance (Fig. 4C) the differences were also significant $(\mathrm{p}<0.05)$ showing that, as expected, copepods drive the abundance of mesozooplankton. In order to suppress the seasonal variability, copepodites plus copepods were pooled together considering the highest values of the second quarter of the moon as the $100 \%$ of abundance (Fig. 5). Since only two lunar cycles showed values in the first quarter of the moon, this was excluded from the figure. A clear decrease in abundance was observed from the second to the fourth quarter of the moon (ANOVA, $\mathrm{p}<0.05$ ), showing a rather high variability in the days between both moon illumination periods.

These results give additional support to the presence of a lunar cycle in mesozooplankton in subtropical waters. Because data on zooplankton biomass are based on 0-200 $\mathrm{m}$ hauls, the effect of changes in abundance in the moon illuminated layers should not be as clear as if sampling were restricted to the i.e. upper $100 \mathrm{~m}$ layer, the layer most affected by changes in moon illumination. However, it shows that changes in abundance are not related to daytime changes in the vertical distribution of epipelagic copepods in the 0-200 m layer. The main problem in the interpretation of the compiled data is related to the high variability in zooplankton biomass among seasons. The highest zooplankton abundance were observed during the second quarter of the moon coinciding with the increase in the moon illumination, although this result could be biased by the seasonal changes in abundance. Nevertheless, when the seasonal variability is subtracted by normalising the data (Fig. 5), it can be observed that abundance was significantly lower

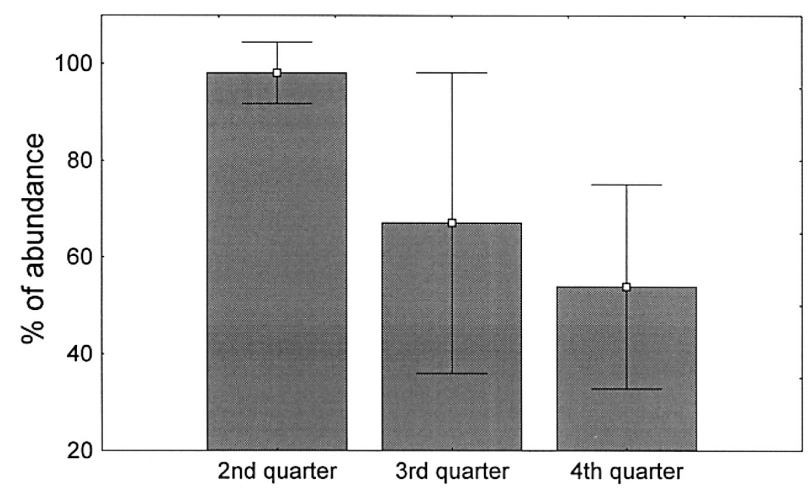

FIG. 5. - Percentage of copepodites plus copepods grouped in relation to the second, third and fourth quarter of the moon. Values during the second quarter of the moon were converted to $100 \%$ of abundance in order to subtract the seasonal variability. Vertical lines as in Figure 3.

during the new moon period. This is in agreement with the results of Gliwicks (1986) who observed higher abundance during the second quarter of the moon in freshwater zooplankton. The differences in abundance found in the present work and in a previous study (Hernández-León, 1998) highlight the role of predation in structuring the marine pelagic ecosystem (Verity and Smetacek, 1996). Moreover, the differences in abundance during the full and new moon phases suggest that there is a net flux of energy from the euphotic to the mesopelagic zones through the diel vertical migrants. Energy transferred from primary producers to mesozooplankton in the shallower layers of the ocean would be transported to deep waters due to predation by diel vertical migrants. This is in agreement with observations made in the Canary Island waters by HernándezLeón et al. (1984) who observed an increase in biomass at mesopelagic depths after the increase of biomass in the upper $200 \mathrm{~m}$ depth during the late winter bloom.

The importance of this process in the so-called active flux component of the biological pump in subtropical waters needs to be evaluated. A 30-day periodicity in the sinking (gravitational) flux has been observed with deep sediment traps in subtropical waters of the Atlantic ocean (Khripounoff et al., 1998). This feature could be explained by the lunar periodicity in abundance of mesozooplankton described above. On the other hand, our results may shed some light on the interpretation of the uncoupling normally observed between primary production and export flux. Further studies have to be made with shorter periods of sampling in order to corroborate this pattern of variation in zooplankton biomass and abundance in subtropical waters. 


\section{ACKNOWLEDGEMENTS}

This work was partly supported by projects FRENTES (CICYT, AMB95-0731) and MESOPELAGIC (CICYT, MAR97-1036).

\section{REFERENCES}

Boden, B.P. and E.M. Kampa. - 1967. The influence of natural light on the vertical migrations of an animal community in the sea. Symp. Zool. Soc. London, 19: 15-26.

Clarke, T.A. - 1973. Some aspects of the ecology of lanternfishes (Myctophidae) in the Pacific Ocean near Hawaii. Fish. Bull., 71: 401-434.

Fernández de Puelles, M.L. - 1986. Ciclo anual de la comunidad de meso y microzooplankton, su biomasa, estructura, relaciones tróficas y producción en aguas de Canarias. PhD. Thesis. Universidad Autónoma de Madrid, 335 pp.

Fernández de Puelles, M.L. - 1987. Evolución anual de microzooplankton en aguas de las Islas Canarias. Bol. Inst. Esp. Oceanogr., 4: 79-90.

Fernández de Puelles, M.L. and J. García-Braun. - 1989. Dinámica de las comunidades plantónicas en una zona del Atlántico subtropical (Isla de Tenerife). Bol. Inst. Esp. Oceanogr., 5: 87-100.

Fernández de Puelles, M.L. and J. García-Braun. - 1996. Micro and mesozooplankton in Canarian waters $\left(28^{\circ} 30^{\prime} \mathrm{N}, 16^{\circ} 06^{\prime} \mathrm{W}\right)$. In: O. Llinás, J.A. González and M.J. Rueda (eds.), Oceanography and Marine Resources in the Eastern Central Atlantic, pp 6989. DGUI Gobierno de Canarias-Cabildo Insular de Gran Canaria.

Gliwicz, Z.M. - 1986. A lunar cycle in zooplankton. Ecology, 67: 883-897.

Hernández-León, S. - 1998. Annual cycle of epiplanktonic copepods in Canary Island waters. Fish. Oceanogr., 7: 252-257.

Hernández-León, S., O. Llinás and J.G. Braun. - 1984. Nota sobre la variación de la biomasa mesozooplanctónica en aguas del Archipiélago Canario. Inv. Pesq., 48: 495-508.

Hill, M.N. - 1962. The Sea (vol. 1), Interscience, New York.

Huntley, M.E. and M.D.G. Lopez. - 1992. Temperature-dependent production of marine copepods: A global synthesis. Am. Nat., 140: 201-242.

Khripounoff, A., A. Vangriesheim, and P. Crassous. - 1998. Vertical and temporal variations of particle fluxes in the deep tropical Atlantic. Deep-Sea Res. I, 45: 193-216.

Roger, C. - 1974. Influence de la phase et de l'éclairement lunaire sur les répartitions verticales nocturnes superficielles de crustacés macroplanctoniques (Euphausiacea). Cah. O.R.S.T.O.M., sér. Océanogr., 12: 159-171.

Tarling, G.A., F. Buchholz and J.B.L. Matthews. - 1999. The effect of a lunar eclipse on the vertical migration behaviour of Meganyctiphanes norvegica (Crustacea: Euphausiacea) in the Ligurian Sea. J. Plankton Res., 21: 1475-1488.

Verity, P.G. and V. Smetaceck. - 1996. Organism life cycles, predation, and the structure of marine pelagic ecosystems. Mar. Ecol. Progr. Ser., 130: 277-293. 
